\title{
The big push, natural resource booms and growth
}

\author{
Jeffrey D. Sachs, Andrew M. Warner *
}

\begin{abstract}
A simple application of big-push reasoning suggests that natural resource booms can be important catalysts for development in poorer countries. In this paper we present evidence from seven Latin American countries that natural resource booms are sometimes accompanied by declining per-capita GDP. We present a model with natural resources, increasing returns in the spirit of big push models, and expectations to clarify some of the reasons this may happen. (C) 1999 Elsevier Science B.V. All rights reserved.
\end{abstract}

JEL classification: $\mathrm{O} 4 ; \mathrm{Q} 33$

Keywords: Growth; Natural resource booms; Big push

\section{Introduction}

If low-income equilibrium traps are important in economic development-so that a big push is necessary for development - then natural resource booms can be potentially important catalysts for growth and development. After all, the big push literature, exemplified by Rosenstein-Rodan $(1943,1961)$ and Murphy et al. (1989), stresses that poor economies need some sort of large demand expansion, to expand the size of the market, so that entrepreneurs will find it profitable to incur the fixed costs of industrialization. In the big-push logic, anything that stimulates demand will do, whether a large public spending program, foreign aid, discovery of minerals, or a rise in the world price of a natural resource. Furthermore, a casual examination of the numbers suggests that the potential impact of natural

\footnotetext{
* Corresponding author. HIID One Elliot Street Cambridge, MA 02138, USA. Fax: + 1-617-4950712; E-mail: awarner@hiid.harvard.edu
} 
resource booms (defined as either a discovery or an exogenous world price increase) on aggregate demand certainly seems to rival that of a typical public expenditure program. To take some examples from recent history in Latin America, in Bolivia, over an 9-year period between 1975 and 1984, revenue from natural resource exports rose from $11 \%$ of GDP to $23 \%$ of GDP, a rise of $12 \%$ of GDP. In Ecuador, in just two years between 1972 and 1974, primary export revenue rose by 19\% of GDP. In Mexico, between 1978 and 1983, revenue from oil exports increased by $6 \%$ of GDP.

The big push potential of commodity booms certainly has been recognized by analysts in resource-rich Latin American countries. In a well known phrase, Venezuelan politicians speak of using oil revenues to 'sow the seeds' of economic development. Indeed, for most of its history, Latin America has been one of the leading laboratories for natural resource booms and busts. After the dust had settled from the Napoleonic wars and the struggles for independence in the early-nineteenth century, the foundations for the commodity lottery were put in place around the continent. Silver production doubled in Peru in the 1830's. Gold production doubled in Mexico between 1820 and 1840. Copper production rose by a factor of about 7 in Chile prior to 1850, and Cuba had a major boom in Sugar production. Later in the nineteenth century, Coffee production grew steadily in Brazil, Colombia and Costa Rica. Peru had its Guano boom around 1850, and Chile had a nitrate boom in the late 1890's. Oil production emerged in the twentieth century in Venezuela and Ecuador (the facts are from Bulmer-Thomas, 1994).

The question this paper addresses is whether natural resource booms are beneficial in the way that the big push reasoning would suggest - by providing the catalyst for low-income economies to overcome the fixed costs of industrialization. This question is a subset of the broader question of whether specialization in natural resources is a viable strategy for successful economic development. On the broader question, several recent case studies have documented the problems with natural-resource-led development in specific countries or groups of countries, see for example Auty (1990) and Gelb (1988). There is also recent cross-country evidence of an inverse association between natural resource intensity and percapital growth between 1970 and 1990 (Sachs and Warner, 1997a,b). This cross-country evidence, however, needs to be complemented by time series evidence to study the impact of commodity booms on long term growth. This is potentially an important issue because it is an open question whether the observed negative association between growth and natural resource abundance is due to the fact that natural resource abundant countries are more likely to experience booms, busts and the accompanying uncertainty, or whether something else about resource abundance causes slower growth over the long term.

Turning back to Latin American history, although we lack sufficient GDP data for the period before the mid-twentieth century, there is some evidence that the nineteenth century booms had a positive effect on long-run development. Cuba 
became the first country in the region to construct a railway in 1838 after its sugar boom (Bulmer-Thomas, 1994, p. 35) and the Guano boom in Peru led to the establishment of banks for the first time in the 1860's (Randall, 1977, p. 110). Yet the record is far from the unmitigated success that one might expect from a naive application of the big push reasoning. Partly as a result, while the development strategy led by natural resource exports was not seriously questioned in Latin America in the nineteenth century, it has come under increasing challenge in this century. To be sure, an important impetus for this challenge was the interwar experience with declining commodity prices, and the early-postwar view associated with Singer (1950) and Prebisch (1950) that commodity prices were on a secular decline. But the critique runs deeper than this, and has persisted even after the evidence overturned the view that commodity prices were on a secular decline. A leading text on the economic history of Latin America concludes that overall, the experience with primary-export-led development has been a failure (BulmerThomas, 1994, p. 344).

To focus on the economic effects of resource booms on growth, this paper starts with a brief review of some of the findings from cross country research. Then we identify five country-episodes from recent Latin American history where we have both an identifiable natural resource boom as well as time series data on GDP. We then look at these cases and try to make some modest generalizations. One of the tentative conclusions that emerges is that there doesn't seem to be a single case where GDP growth was obviously faster after the boom was finished than before the boom started, as the big push reasoning would suggest. If anything, GDP growth seems to be slower in several cases after the boom period. Naturally, there are issues about whether these conclusions would remain after controlling for other factors affecting growth, which we discuss, but the simple evidence is far from supportive of the idea that booms should serve as catalysts for development.

While a definitive answer to the question of whether booms invariably bring on slow growth awaits more data, the evidence is nevertheless sufficiently suggestive to raise the possibility that resource booms can result in slower growth. With this as motivation, the rest of the paper presents a model to better understand the role of a big push in a natural resource intensive economy, and the conditions under which growth may actually be depressed as a result of a natural resource boom.

Existing explanations for the disappointing performance of resource booms tend to fall into two categories. First there is the earlier development literature in the tradition of Hirschman (1958) that stressed that natural resource booms had poor backward and forward linkages, and thus had small impacts on other sectors of the economy. In addition, there is the common perception of observers in booming economies that revenues from booms are consumed rather than invested. Both of these explanations can explain why GDP in booming economies ends up lower than it might have been with better linkages or more investment, but they do not explain an actual decline or a fall in the growth rate after the boom has run its 
course. Something more pernicious must be going on to account for slower growth.

The model in this paper borrows from the models in the big push literature in which the driving force in development is the transition from cottage industry to factory production. For entrepreneurs to be willing to make this transition, they must expect that other entrepreneurs will also want to industrialize, so that factory production can become sufficiently profitable to justify their choice. We show that in this setting, natural resource booms can stimulate industrialization, as in the big push story, but can also frustrate and even reverse industrialization that is in mid-stream. The timing of the natural resource boom matters, and so does the sectoral distribution of the increasing returns and whether the boom stimulates the right sectors.

\section{Recent findings from cross-country research}

We have presented evidence in previous research that there has been an inverse association across countries between natural resource abundance and economic growth over the period 1970-1990 (see Sachs and Warner, 1995 for the basic argument, or, for additional and updated results, see Sachs and Warner, 1997a,b). Previously, both Gelb (1988) and Auty (1990) examine, among other things, the hypothesis of a 'curse of natural resources', documenting many of the development problems of natural resource-intensive economies, without however, showing the inverse association on the basis of a cross country study. For an example of the kind of result one obtains with cross-country data, we present growth regression estimates in Table 1, adapted from Sachs and Warner (1997a,b). The variables used in the regression are described in Appendix A.

These regressions show the negative association between resource abundance and growth, even after controlling for a number of additional variables. The estimated coefficient in the first regression on the natural resource export variable $(-3.26)$ implies that an increase of one standard deviation in this variable $(+0.12)$ was associated with a reduction in annual average growth of $0.39 \%$. Over a 20-year period, this effect would reduce per-capita GDP by about $7 \%$, other things constant. In the second regression in Table 1 , we add a dummy variable for the eleven countries included in this paper. We show that this variable is not significant, in order to demonstrate that the eleven countries in this paper are not, on average, unusual in their growth experience. In the third regression, we replace the natural resource export variable, which includes exports of primary agriculture and basic metals and minerals, with an alternative measure of natural resource exports that includes only basic metals and minerals. The regression shows that this variable is also negatively associated with growth, with a slightly higher estimated coefficient (higher in absolute value). We include this result because later in this paper, we will use data on mineral exports in some of the countries to 
Table 1

Cross-country regression estimates. Dependent variable: growth per-capita of ppp-adjusted GDP, 1965-1990

\begin{tabular}{|c|c|c|c|c|}
\hline Log of real GDP per economically-active population in 1965 & $-1.63(-8.47)$ & $-1.57(-7.63)$ & $-1.72(-8.11)$ & $-1.63(-8.48)$ \\
\hline Openness times log GDP per e.a. in 65 & $-0.77(-2.54)$ & $-0.83(-2.67)$ & $-0.57(-1.83)$ & $-0.84(-2.77)$ \\
\hline Openness to international trade (share of years open $65-90$ ) & $8.48(3.44)$ & $9.00(3.54)$ & $6.93(2.69)$ & $9.04(3.65)$ \\
\hline Land-locked dummy variable & $-0.58(-2.69)$ & $-0.54(-2.48)$ & $-0.67(-2.87)$ & $-0.58(-2.55)$ \\
\hline Log life expectancy circa 1970 & $45.48(2.60)$ & $44.84(2.56)$ & $40.09(2.23)$ & $38.54(2.19)$ \\
\hline Square of log life expectancy & $-5.40(-2.41)$ & $-5.31(-2.36)$ & $-4.70(-2.03)$ & $-4.49(-1.99)$ \\
\hline Central government saving, $70-90$ & $0.12(5.40)$ & $0.12(5.30)$ & $0.14(5.69)$ & $0.14(5.89)$ \\
\hline Dummy for tropical climate & $-0.85(-3.64)$ & $-0.84(-3.59)$ & $-1.13(-4.79)$ & $-0.88(-3.74)$ \\
\hline Institutional quality index & $0.28(3.95)$ & $0.28(3.80)$ & $0.23(3.19)$ & $0.25(3.42)$ \\
\hline Natural resource exports /GDP 1970 & $-3.26(-3.41)$ & $-3.34(-3.47)$ & - & $-3.17(-3.31)$ \\
\hline Growth in e.a. pop minus pop growth & $1.19(3.82)$ & $1.21(3.86)$ & $1.51(4.58)$ & $1.15(3.68)$ \\
\hline Dummy for 11 South American countries in this paper & & $-0.20(-0.84)$ & & \\
\hline Mineral exports /GDP 1970 & & & $-4.49(-2.44)$ & \\
\hline Standard deviation of terms of trade index & & & & $-0.012(-1.55)$ \\
\hline Adjusted $R^{2}$ & 0.89 & 0.89 & 0.88 & 0.89 \\
\hline Number of countries & 79 & 79 & 76 & 76 \\
\hline
\end{tabular}

Source: modified versions of regression estimates in (Sachs and Warner, 1997a,b). See Appendix A for description of variables. T-ratios in parentheses. 
measure natural resource booms over time. Finally, in the last regression in Table 1 , we show that the negative association between natural resource exports and growth is unaffected by the inclusion of a variable to measure volatility in natural resource prices. The variable we use is the standard deviation over the twenty-year period (1970-1990) of each countries external terms of trade. The volatility variable is itself weakly, negatively, associated with growth.

To explain the negative association between natural resource abundance and growth, we presented a dynamic Dutch disease model but remain open to other explanations (Sachs and Warner, 1995). The core of the Dutch disease story is that resource abundance in general or resource booms in particular shift resources away from sectors of the economy that have positive externalities for growth. Other possible explanations focus on the effects of natural resource abundance on human or physical capital accumulation, corruption and institutional quality, or endogenous policy choices.

The cross-country evidence sheds some light on these explanations. For example, there is no robust association between natural resource abundance and any of the following: national saving, national investment or rates of human capital accumulation, at least when the latter is measured in terms of average years of schooling. There is an inverse association between natural resource abundance and several measures of institutional quality. This result is based on the institutional quality measures in (Knack and Keefer, 1994), and is presented in (Sachs and Warner, 1997a,b, Table 11). However, since the alternative institutional quality measures are themselves highly positively correlated across countries, the data do not allow us to be very precise about exactly which aspects of institutional quality are related to natural resource abundance, or in turn, exactly which are relevant for growth. There is also some preliminary evidence that over the period 1970-1990, natural resource abundance and trade openness were related in a u-shaped pattern. That is, at low levels of resource abundance, more resource abundant countries were more likely to be protectionist (Taiwan is more open than Venezuela for example), but at higher levels of resource abundance, more resource abundant economies were more likely to be open (Venezuela is less open than Saudi Arabia for example).

Regarding Dutch disease notions, there is supportive evidence that natural resource abundant countries tended to have a larger service sectors and smaller manufacturing sectors than resource-poor economies (Sachs and Warner, 1997a,b, Table 8). There is also evidence that natural resource abundant countries tended to have slower growth in exports of manufactures than did resource poor-economies (Sachs and Warner, 1997a,b, Table 8). This regression supporting this last result is reproduced in Table 2. The dependent variable is the change in the ratio of exports of manufactures to total exports. The results show that countries that followed open trading policies tended to have higher growth in manufacturing exports, and that, after controlling for this, resource-poor countries tended to have slower growth in manufacturing exports. If exports of manufactures are an important 
Table 2

Regression estimates of the association between natural resource intensity and growth in exports of manufactures, 1970-1989

\begin{tabular}{lc}
\hline & Increase in manufacturing export share 1970-1989 \\
\hline Natural resource exports /GNP & $-0.47(-2.41)$ \\
Openness to trade & $0.19(3.44)$ \\
Initial manufacturing export share, 1970 & $-0.46(-4.72)$ \\
Adjusted $R^{2}$ & 0.19 \\
Sample size & 88 \\
Standard error & 0.18 \\
\hline
\end{tabular}

See Appendix A for variable definitions. $T$-ratios in parentheses.

engine of growth, and if the Dutch disease effects of natural resource abundance tends to squeeze this sector, then this provides a channel for the negative association between natural resource abundance and growth.

To gauge the importance of natural resource abundance in accounting for slower growth among the eleven Latin American countries in this paper, the third column of Table 3 multiplies the estimated regression coefficient by the natural resource intensity variable for each country. At the high end, the results suggest that Venezuelan growth was $0.77 \%$ lower due to natural resource intensity. Taken literally, this implies that at the end of the 20-year period in 1990, Venezuelan per-capita GDP was about $14 \%$ lower than it would have been if Venezuelan had no natural resources.

Table 3

Basic data on natural resource intensity and growth, 11 Latin American countries

\begin{tabular}{llll}
\hline Country & $\begin{array}{l}\text { Natural resource } \\
\text { exports percent } \\
\text { of GDP, 1970 }\end{array}$ & $\begin{array}{l}\text { Growth in GDP } \\
\text { per-capita, } \\
1965-1990\end{array}$ & $\begin{array}{l}\text { Regression estimate } \\
\text { of the natural } \\
\text { resource effect }\end{array}$ \\
\hline Argentina & 0.053 & -0.586 & -0.172 \\
Bolivia & 0.185 & 0.433 & -0.602 \\
Brazil & 0.055 & 2.332 & -0.179 \\
Chile & 0.149 & 0.230 & -0.485 \\
Colombia & 0.094 & 1.327 & -0.307 \\
Ecuador & 0.106 & 1.637 & -0.344 \\
Mexico & 0.024 & 0.496 & -0.079 \\
Paraguay & 0.097 & 1.212 & -0.316 \\
Peru & 0.153 & -1.666 & -0.498 \\
Uruguay & 0.091 & 0.656 & -0.297 \\
Venezuela & 0.237 & -2.200 & -0.772 \\
\hline
\end{tabular}

See Appendix A for further information on the variables in the first two columns. The third column is the natural resource intensity variable (in column 1) times the estimated regression coefficient on this variable from Table 1 regression 1. 


\section{Recent natural resource booms in Latin America}

We turn now to the evidence on recent natural resource booms in Latin America. We have examined eleven major Latin American economies over the period 1960-1994 (data permitting) to identify whether, and when, a boom occurred: Argentina, Bolivia, Brazil, Chile, Colombia, Ecuador, Mexico, Paraguay, Peru, Uruguay, and Venezuela. Our assessment is that there was a significant natural resource boom in four countries: Bolivia, Ecuador, Mexico, and Venezuela; there was no boom in another four countries: Argentina, Brazil, Paraguay and Uruguay; and there is mixed evidence of a boom in another three countries: Chile, Colombia and Peru.

To arrive at these conclusions, we looked at time-series evidence on realized exports of natural resources divided by GDP for each of these countries. We also looked at evidence on the external terms of trade for each country, but it soon became clear that the terms of trade evidence was potentially misleading because it measured only price movements, while both price and quantity movements are relevant for measuring natural resource booms. This distinction is especially relevant for Ecuador and Mexico, since discoveries of new oil deposits were important in both country's natural resource booms. Our definition of a natural resource boom is a rise in the realized natural resource exports to GDP of at least $4 \%$ of GDP, from beginning to the peak of the boom, with a duration of at least three years. In the figures presented in Appendix B, as well as in Table 4, we present the evidence behind our dating of the booms.

Table 4

Natural resource booms: selected Latin American countries

\begin{tabular}{|c|c|c|}
\hline Country & Dates & $\begin{array}{l}\text { Magnitude-trough to peak } \\
\text { (in percent of GDP) }\end{array}$ \\
\hline \multicolumn{3}{|c|}{1.4 clear cases of natural resource booms } \\
\hline Bolivia & $1973 / / 1975-1987$ & $13 \%$ \\
\hline Ecuador & $1972-1986$ & $10 \%$ \\
\hline Mexico & $1978-1986 / / 1988$ & $8 \%$ \\
\hline Venezuela & $1972-1986$ & $7 \%$ \\
\hline \multicolumn{3}{|c|}{2.3 cases where the dating of the boom is ambiguous } \\
\hline Chile & $1965-1972,1972-1977$ & $6-8 \%$ \\
\hline Colombia & $1975-1981,1981-1988$ & $4-5 \%$ \\
\hline Peru & $1975-1981,1981-1986$ & $6 \%$ \\
\hline \multicolumn{3}{|c|}{3.4 cases where there was no major natural resource boom } \\
\hline Argentina & - & - \\
\hline Brazil & - & - \\
\hline Paraguay & - & - \\
\hline Uruguay & - & - \\
\hline
\end{tabular}

The dating represents the authors judgments based on the data in Appendix B. See the text for the discussion. 
What we try to do in dating the boom is to identify the year just before the ratio of primary exports to GDP rose significantly and also identify the year when the primary export ratio was approximately back to its pre-boom level. What we are after is well illustrated by the case of Bolivia, depicted in Appendix B. The export ratio was fairly constant in the 1960s and first started to rise significantly in after 1973. It dipped back down temporarily in 1975 but thereafter was very high until 1985. After 1985 it declined precipitously so that by 1987 it was back below the 1973 value. In Bolivia's case, it is unclear whether the starting date should be 1973 or 1975 , but the terminal date is fairly clear, and it is also clear that the export ratio was significantly higher in the period between 1975-1985 than in the years before or after. As can be seen from this example, we date the boom as trough to trough, rather than trough to peak. Our reason is that we want to separate the question of the direct effect of the booms on GDP growth from the question of whether the boom sets in motion forces which have a lasting effect on growth. We are interested in the second question, which requires a comparison of the path of GDP before the boom started, with the path of GDP after the boom has fully run its course.

Our dating of the natural resource booms is summarized in Table 4. We separate the countries into three groups: those with a clearly identifiable natural resource boom; those with a less clearly identifiable boom; and those with no significant boom. Bolivia, Ecuador, Mexico and Venezuela are in the first group. The boom in Ecuador and Venezuela coincide approximately with the rise and decline in oil prices from 1973-1986. Mexico's boom started somewhat later, in 1978, and ended either in 1986 or 1988. Bolivia's boom ran from either 1973 or 1975 to 1987.

In Appendix $\mathrm{C}$ we plot the path of the log of GDP per-capita for each of these four countries. Out of the four countries, only in Ecuador was the level of GDP significantly higher after the boom ended. In Bolivia and Venezuela it was actually much lower, and in Mexico it was about the same. Three of the four countries exhibited an initial rise and then a collapse in GDP during the boom period. Furthermore, it is not obvious in any of the countries that GDP growth was faster in the period after the boom than in the period before the boom. This was clearly the case in Bolivia and Mexico and Venezuela, and somewhat less clear in the case of Ecuador. Overall, there was no consistent pattern of a takeoff in GDP in these four cases; growth declines were not uncommon; and even the level of GDP was not invariably higher after the end of the boom.

When we look at the path of GDP in the three cases where a boom is more difficult to date, there is still no consistent evidence of a positive effect on GDP, even though the evidence is more difficult to interpret. Chile may be said to have experienced a boom during 1965-1972, or 1972-1977, or arguably over the entire period 1965-1977, but Chile's rapid growth occurred after 1982, when copper prices collapsed. Few observers attribute a major role to copper prices in Chile's growth after 1982. Instead, the 1982 devaluation, financial reform, pension reform, 
and privatization are more often given credit (Collier and Sater, 1996, p. 321). Colombia's period of rapid growth occurred during the late 1960's and early 1970s, before the coffee booms of the late 1970s. Irrespective of whether one dates the boom period in Colombia as 1975-1981 or 1975-1988, overall growth during this period was not clearly higher than before the boom; nor was overall growth after this period. It seems fair to say that Colombia's coffee booms did not have a lasting effect on either the level or growth in GDP. In the case of Peru, the boom period again is difficult to date, because there were two back to back booms covering the periods 1975-1981 and 1981-1986. The entire period however was one of instability without any overall growth in per-capita GDP, contrasting sharply with positive growth before the boom. After the boom per-capita GDP in Peru declined precipitously. The boom period and its aftermath seems to have reversed more than a decade of positive growth between 1960 and 1974 .

To summarize the seven cases we have examined, we see one case (Ecuador) where the boom may have had a positive, lasting effect on per-capita GDP, two cases (Chile and Colombia) where there was probably no major effect in either direction, and four cases (Bolivia, Mexico, Peru and Venezuela) where per-capita GDP actually declined during and/or after the boom period. The rest of this paper presents a model to explain this diversity of experience with natural resource booms.

\section{A model of natural resource booms and industrialization}

We consider an economy in which there are increasing returns to scale in one of the sectors, so that a big push is potentially beneficial, and which is also capable of international trade and natural resource production. The economy produces two consumption goods, and one natural resource which is traded and not consumed domestically. One of the consumption goods is produced with labor alone, the other is produced with $N$ intermediate goods that in turn employ labor (there is no capital in the model). The intermediate goods can be produced with declining average costs, so that the sector that employs the intermediate goods can exhibit increasing returns to scale. One of the main points of the model is to contrast the impact of a natural resource boom when the output of the increasing returns sector is either traded or non-traded.

Our introduction of increasing returns is similar to the formalization of the big push in (Murphy et al., 1989) and the production structure in (Ethier, 1982). In the increasing returns sector, final output is produced by combining the $N$ intermediate inputs into a CES production function.

$$
Q=\left(\sum_{i=1}^{N} x_{i}^{a}\right)^{\frac{1}{a}}, a \in(0,1)
$$


To allow scope for big push ideas, each of the $N$ intermediate inputs can be produced with one of two technologies, a traditional technology or a modern technology. In this regard the model is identical to Murphy et al. (1989). The traditional technology is used by a competitive fringe of firms, called cottage industries, where entry is very easy, competition is perfect, and production is cheaper than the modern technology as long as output is small. The traditional technology is summarized by the production function $x_{i}=l_{i}$, and associated cost function $w l_{i}=w x_{i}$. To capture the idea that the supply of entrepreneurial talent is limited, and that therefore entrepreneurs earn rents, we suppose that each sector also has one entrepreneur with knowledge of a modern production technology. This modern technology may be thought of as a factory that involves setup costs of $\alpha$ units of labor but which is lower cost than the traditional technology at high levels of output. This technology is summarized by $l_{i}=\alpha+\beta x_{i}$, which has associated cost function $w l_{i}=w\left(\alpha+\beta x_{i}\right)$. To bring in the idea that factory production is eventually more efficient than cottage industry production, we assume $\beta<1$. This ensures that if the scale of production is sufficiently large, factory production will cost less than cottage industry production. Specifically, when the scale of output is larger than the critical level given by $x^{*}=\alpha /(1-\beta)$, then factory production costs less that traditional production.

In each intermediate sector, the entrepreneur decides whether to set up a factory and operate with the modern technology, and what price to charge. He will not always choose the standard profit-maximizing price of a monopolist. To see this, note that if the market will support production beyond the critical level $x^{*}$, then the entrepreneur does have the ability to drive the competitive fringe out of business, and thus to operate as a monopolist in his particular sector. The reason is that average cost in the competitive fringe is always $w$, but average cost in factory production will be slightly below $w$ if $x$ is above $x^{*}$. So the entrepreneur could charge a price equal to his average costs and put the cottage industries out of business. However, this would earn the entrepreneur zero-profits: he could achieve higher profits by choosing to price at the average cost of the cottage industries, $p=w$, and pocket the difference between this price and his lower average costs. The entrepreneur would not choose a higher price because he would loose all business to the competitive fringe.

Whether the entrepreneur would wish to raise his price all the way to $p=w$ depends on where the profit-maximizing price lies in relation to $w$ : if the profit-maximizing price is lower than $w$, then the entrepreneur would just charge the profit-maximizing price and ignore the competitive fringe. The entrepreneur can calculate, by solving the problem of the final goods producer in his sector, that the market demand for each intermediate is given by $x_{i}=Q\left(P_{i} / P_{Q}\right)^{-\epsilon}$, where $p_{i}$ is the intermediate price, $p_{Q}$ is the price of the final output, and $-\epsilon$ is the elasticity of demand. $(\epsilon \equiv 1 /(1-a))$. The profit-maximizing price is therefore $p^{*}=w \beta / a$. If the cottage industry price, $w$, is lower than $w \beta / a$, then the entrepreneur can price no higher than $p=w$. In this case the mere presence of the 
cottage industries serves to constrain the pricing behavior of the entrepreneur, even if they don't actually operate. We assume that the parameters are such that we are in this latter case, in which $w<w \beta / a$, or $a<\beta$. This means that in equilibrium, the technology of the competitive fringe effectively sets the price of each intermediate product:

$$
p_{i}=w .
$$

With the price of the intermediate good equal to $w$, and identical across sectors, the producer of the final good will demand identical quantities of each intermediate, equal to $x=Q\left(p / p_{Q}\right)^{-\epsilon}$. Substituting this into the production function above, we have $Q=N^{1 / a} Q(p / p Q)^{-\epsilon}$, which simplifies to

$$
p_{Q}=p N^{\frac{-(1-a)}{a}} \text {. }
$$

Since output of each intermediate is the same, final output in the increasing returns sector is simply.

$$
Q=N^{\frac{1}{a}} x
$$

Labor demand in this increasing returns sector depends in part on the number of factories in operation, since they employ labor in different quantities than the cottage industries. Generally, with $n$ denoting the number of the $N$ sectors operating as factories, and $L^{j}(j=N, T)$ denoting total labor employed in the sector, the full-employment relation is

$$
L^{j}=(N-n) x+n(\alpha+\beta x) .
$$

In later sections of this paper it will prove convenient to solve this equation for $x$ and write the level of output in each intermediate sector that is required to fully employ $L^{j}$ units of labor, conditional on $N, n$ and the technology parameters.

$$
x=\frac{L^{j}-n \alpha}{N-n(1-\beta)}
$$

It is worth stressing that the presence of the competitive fringe of cottage industries, together with the assumption that $a<\beta$ means that the product price for each entrepreneur operating a factory is independent of the scale of his output, $x$. With the product price and the wage fixed, and average costs declining with the scale of output, profits are a simple increasing function only of the scale of output. This can be seen from the definition of profits below, denoted by $\pi$ (note that $\beta<1)$

$$
\pi=p x-w(\alpha+\beta x)
$$

That completes the description of the increasing returns sector. There are two other sectors which have a simple production structure. First, there is a competitive sector producing with the constant returns to scale production function $Q^{j}=\theta L^{j}$. With free entry, profits are driven to zero so that $p^{j}=\theta w$. Second, 
there is a natural resource sector that produces a constant flow of output of the natural resource, denoted $R$. We do not distinguish movements in $R$ due to changes in the world price of the resource versus new production or discoveries.

On the demand side, we assume that preferences are Cobb-Douglass so that the economy desires fixed expenditure shares on the two consumption goods. Since we will later label one of the consumption goods as traded and the other as not traded, we write this conditions with the superscripts $\mathrm{N}$ and $\mathrm{T}$.

$$
p^{\mathrm{T}} C^{\mathrm{T}}=\psi p^{\mathrm{N}} C^{\mathrm{N}}
$$

To complete the model, we also require the labor market to clear,

$$
L=L^{\mathrm{N}}+L^{\mathrm{T}},
$$

production to equal consumption of the non-traded good,

$$
Q^{\mathrm{N}}=C^{\mathrm{N}}
$$

and the balance of payments condition to hold for the traded good,

$$
C^{\mathrm{T}}=Q^{\mathrm{T}}+R \text {. }
$$

As mentioned above, we will solve two variants of the model: one where the non-traded sector is the increasing returns sector and the other where the traded sector is the increasing returns sector.

As an example of the solution to the model, when the non-traded sector is the increasing returns sector, we choose the wage as the numeraire, $w=1$. This implies that the intermediate goods price, $p$, is also 1 , and the price of the traded good is $\theta$. The price of the non-traded good is given by the equation $p^{n}=$ $N^{-(1-a) / a}$. These equations determine all of the relative good prices in the model. The rest of the solution can be obtained by solving Eqs. (4), (6)-(11). In Appendix A we summarize the equations of the model and the reduced-form solution for $L^{\mathrm{N}}$ for the two cases (non-traded is IRS and traded is IRS).

The model can now be solved to express all the variables of interest as functions of the total number of varieties of the intermediate, $N$, and the number of sectors, $n$, in which the entrepreneur chooses to establish a factory. However, it is clear that if all entrepreneurs could simultaneously choose whether or not to establish a factory, $n \in(0, N)$ cannot be an equilibrium. Since all entrepreneurs face the same technology and demand conditions, if any find it profitable to operate their factory, all would find it profitable. So the only equilibria would be for nobody to industrialize $(n=0)$ or everybody to industrialize $(n=N)$.

We rule out this kind of instant industrialization or de-industrialization by allowing $n$ to be a state variable that can only adjust with finite speed. In this way we incorporate the idea that factories take time to build and that entrepreneurial talent is not instantly and simultaneously available in all the sectors.

Specifically, let us suppose that there is a constant arrival rate of new entrepreneurs and a constant death rate of existing entrepreneurs. Furthermore, let 
us suppose that societies attitudes about the future can be classified into two types: optimism and pessimism, and that these attitudes are identified with expected growth or decline in the number of entrepreneurs establishing factories. We define optimism as the state of affairs where agents in the model expect the number of factories to grow over time; and pessimism where $n$ is expected to decline over time.

To make the mathematics somewhat more tractable, we introduce a variable to represent the share of sectors that have industrialized, $\eta \equiv n / N$. Pessimism is where $\eta$ is expected to decline at a constant rate of decay given by $\lambda: \mathrm{d} \eta / \mathrm{d} t=$ $-\lambda \eta$. Optimism is where $\eta$ is expected to rise by a process where the arrival of new entrepreneurs offsets the natural death of existing entrepreneurs: $\mathrm{d} \eta / \mathrm{d} t=\eta$ $-\lambda \eta$. Therefore, under pessimism, $\eta$ asymptotes to 0 from any initial starting point, and under optimism, $\eta$ asymptotes to 1 from below.

We now are in a position to consider forward-looking equilibria in this model under both optimism and pessimism. Before doing so however, it helps to clarify the relation between $n, x$, and profits. We have already seen that the presence of the competitive fringe in the shadows constrains each factory owner to set $p=w$, and that, because average costs decline with $x$, this means that profits rise linearly with $x$. That covers the relation between $x$ and profits. To understand the relation between $n$ and profits, we need to understand the relation between $n$ and $x$.

As is clear from examining the labor market clearing equation for the intermediate industries, we can see that if one sector were to shift to factory production, all else constant, it would release $x$ units of labor from cottage industry production and would absorb $\alpha+\beta x$ units of labor in the new factory. If we are in the range of $x$ where factories are lower-cost than cottage industry, this transition will result in an excess supply of labor in the increasing returns sector, since if $x>\alpha /(1-\beta), x>\alpha+\beta x$. This situation can be remedied by either an increase in the scale of operation of all intermediate sectors to absorb the additional labor, ( $x$ rises), or by some migration of labor out of the increasing returns sector $\left(L^{j}\right.$ declines), or both. In equilibrium, the adjustment is shared by these two phenomena, that is, $x$ is increasing in $n$ and $L^{j}$ is decreasing in $n$. These results establish that as long as $x$ is sufficiently large that the factories can take advantage of their economies of scale, the profits of each factory will be an increasing function of the number of factories in existence in other sectors. A graph of the relation between profits and $n$ is shown in Fig. 1.

We now return to the question of the forward looking equilibria under optimism and pessimism. For any given value of $n$, we can think of the marginal entrepreneur thinking about setting up a factory or shutting down a factory. If the entrepreneur is optimistic, expecting $n$ to grow, then the profits he will anticipate will grow over time, because $x$ is increasing in $n$ and profits are increasing in $x$. We can define a value function that represents the present discounted value of future profits for each value of $n$. More formally, for any given value $n_{1}$ of $n$, this value function, denoted $V^{\mathrm{o}}\left(n_{1}\right)$, would be the integral over $n \in\left(n_{1}, N\right)$ of 


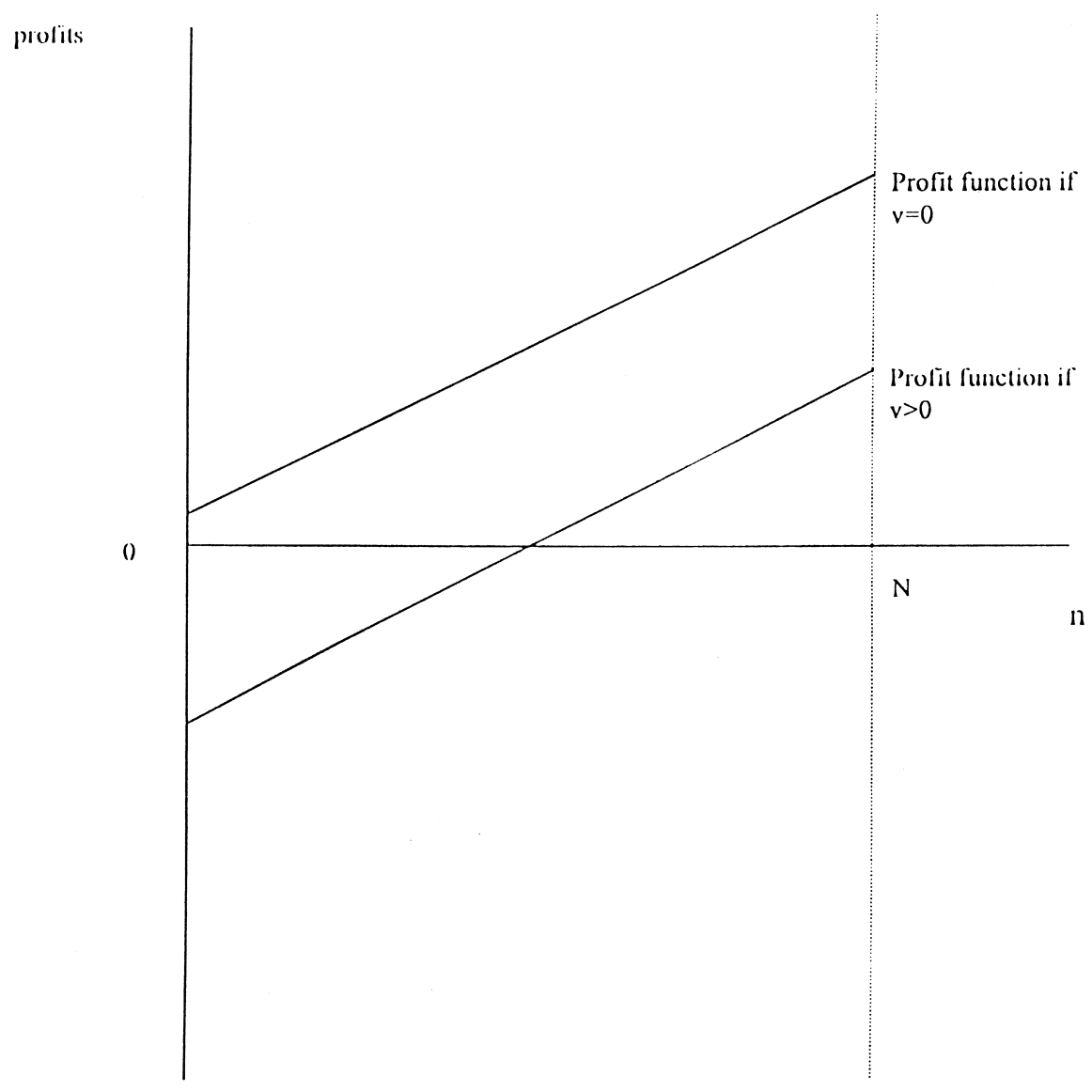

Fig. 1. Profits as a function of $n$.

$\pi(x(n(t)))$. The superscript $\mathrm{o}$ is used to specify that this is the value function for optimistic expectations. Whether $V^{\circ}\left(n_{1}\right)$ rises or declines with $n$, depends on both the position and slope of the profit function, as well as the rate of discount. For some intuition regarding the forces behind the slope, consider the case where profits are always positive as a function of $n$ (for example, the top line in Fig. 1). Then as $n$ increases, the fact that we are integrating over a smaller range of $n$ would serve to reduce the value function, but the fact that the future (higher) profits would be discounted less heavily, would serve to increase the value function. However, we can be sure that as long as profits are positive, then the integral and therefore the value function will also be positive.

The important point is that the condition for profits as a function of $n$ to be positive is the same as the condition for profits as a function of $n$ to be positively 
sloped. Both require that $x$ is sufficiently large that factory production is lower-cost than cottage industry production, i.e., $x>\alpha /(1-\beta)$. This means that, as written so far, only optimistic equilibria exist. The model does not yet have scope for a big push in the sense defined by Murphy et al. (1989). Note that we define an optimistic equilibria for any given value of $n$ to exist whenever the entrepreneur has optimistic expectations and for that value of $n$, the value function is positive, so that entry will occur and $n$ will indeed rise when it is expected to rise. Similarly, pessimistic equilibria exist whenever entrepreneurs expect $n$ to fall and the value function for the pessimistic case is negative. Since in the case we are considering, the profit function is always positive, we have only optimistic equilibria.

This situation is the same as that encountered by Murphy et al. (1989) in their formalization of the theory of the big push. In their formulation, their model only has multiple equilibria when they introduce a wage premium or a compensating differential required to entice workers to migrate from the cottage to the factory. When factories have to pay this wage premium, then the model has the demand spillovers emphasized by Rosenstein-Rodan (1943, 1961). The migration of the marginal worker from the cottage to the factory serves to raise his wage and therefore aggregate demand; hence this can raise the scale of operation that the economy can support in the other sectors. Since Murphy et al. (1989) identify the big push with multiple equilibria, the existence of the wage premium is needed for the model to have scope for a big push.

Therefore, we also introduce a wage premium in order to allow our model to have scope for a big push. Specifically, we assume that to entice workers to migrate from the cottage to the factory, factories must offer a wage of $w(1+v)$, where $v$ is the wage premium. The effect of this, from a technical standpoint, is to make it possible for profits as a function of $n$ to cross 0 , yet still have a positive slope, that is, to have $\pi(n=0)<0$, and $\pi(n=N)>0$. Fig. 1 illustrates this case. (This will only be true for certain values of $v$, so we choose $v$ in this range.)

As shown in Fig. 1, with this wage premium, the profit function can be both positive and negative, and therefore the value functions for either the optimistic case or the pessimistic case can be either positive or negative, so our model is also capable of multiple equilibria. Again, we say that a particular $n$ supports a optimistic equilibria if the optimistic value function for that value of $n$ is positive, and a particular $n$ is negative. In Fig. 2 we show one example of a value function under optimistic expectations and the corresponding range of $n$ that supports an optimistic equilibrium. In Fig. 3 we show possible value functions under both optimistic and pessimistic expectations.

What can we say in general about the position of these value functions and therefore of the existence of optimistic and pessimistic equilibria? First, we know that there must always be some high values of $n$ where optimistic equilibria exist, and there must always be some low values of $n$ where pessimistic equilibria exists. Both statements follow from the fact that profits rise with $n$, together with 


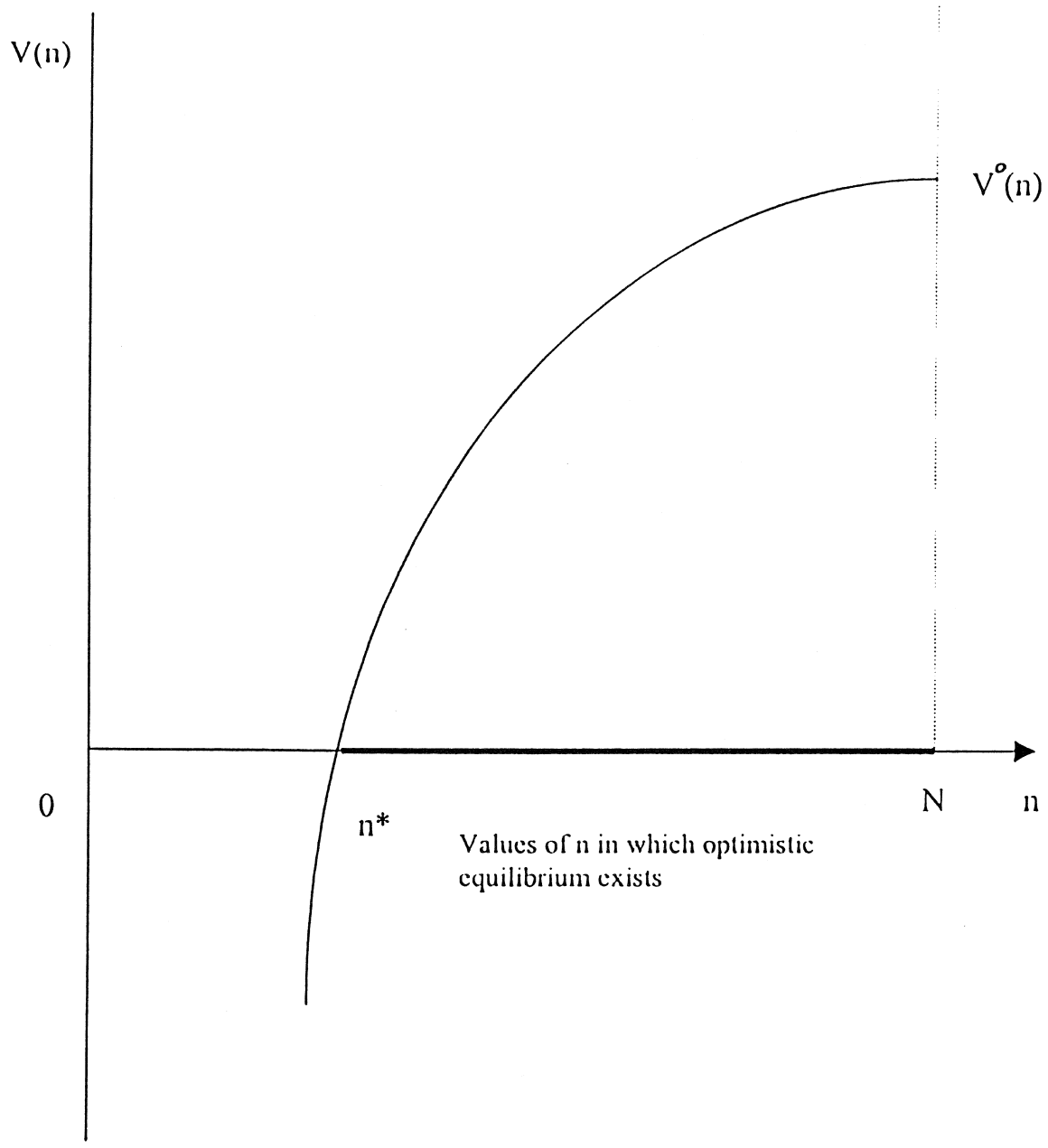

Fig. 2. Example of optimistic value function.

the fact that the optimistic value function involves integrating the area under the profit function to the right while the pessimistic value function involves integrating the area to the left (the intuition can be obtained by looking at the profit function that crosses the 0 axis in Fig. 1). Second, it can also be shown that it is impossible to find a value of $n$ where $V^{\mathrm{o}}(n)<0$ and $V^{\mathrm{p}}(n)>0$, that is, where neither equilibria exist. The reason is that for the optimistic value function to be negative, we must be in the region of $n$ where the profit function is negative; but in the case, it is impossible for the pessimistic value function to be positive, because profits for values of $n$ further to the left of this point are also negative. 


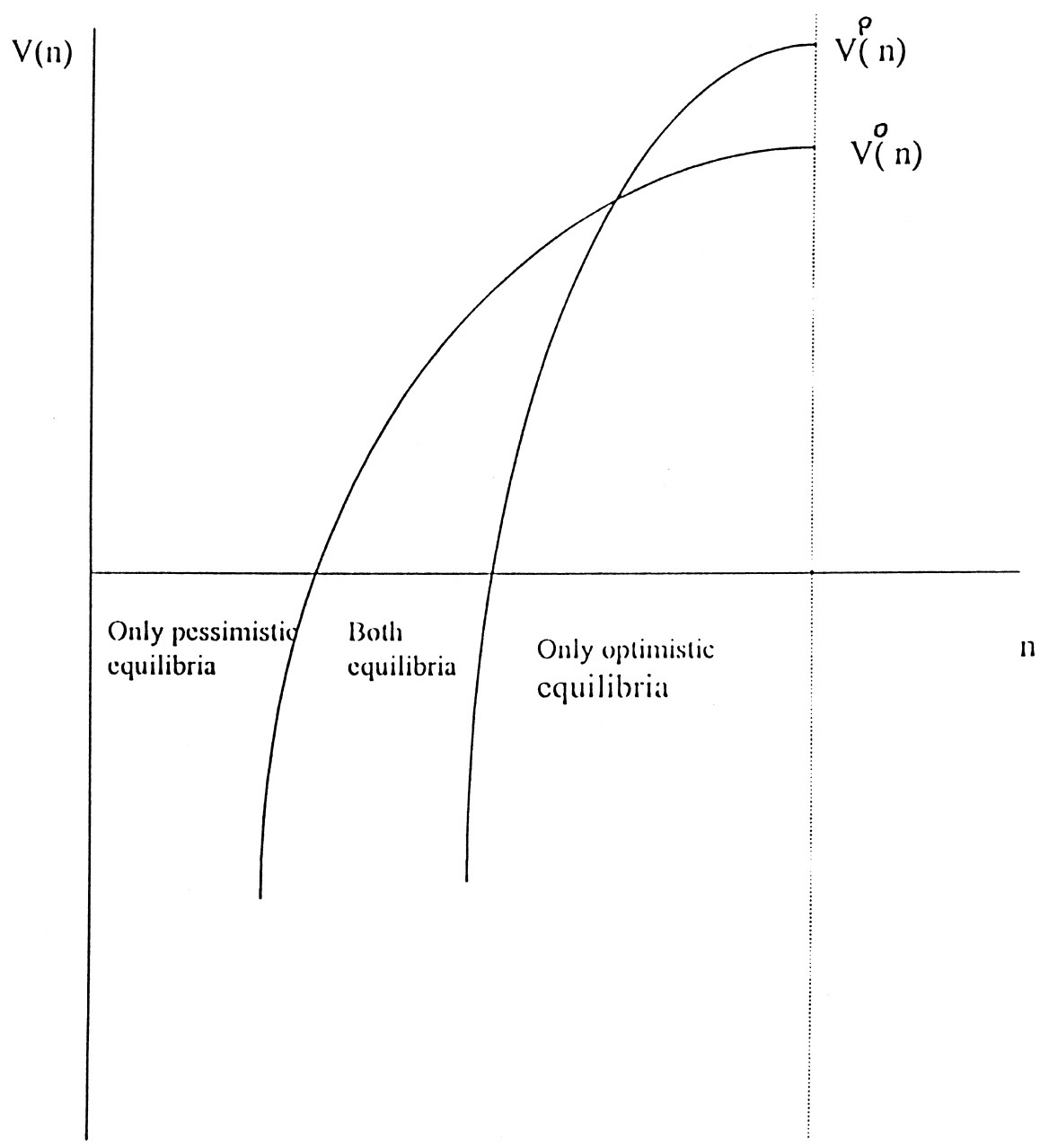

Fig. 3. Optimistic and pessimistic value functions.

And finally, it is possible to find $n$ where both equilibria exist (the $n$ where $\pi(n)=0$ is one such case). In general, then, only three of the four logical possibilities exist in this model. Regions of $n$ support either only optimistic equilibria; only pessimistic equilibria, or both optimistic and pessimistic equilibria.

In Fig. 3 we show the case where all three kinds of equilibria exist. Optimistic equilibria exist for values of $n$ to the right of the point where the optimistic value function intersects the $V=0$ axis, and pessimistic equilibria exist to the left of the point where the pessimistic value function intersects the $V=0$ axis. There is a region to the right where only optimistic equilibria exist, a region to the left where only pessimistic equilibria exist, and a region in the middle where both equilibria 
exist. In the region to the right, the economy will eventually de-industrialize $(n=0)$. In the region in the middle, the economy can either industrialize or de-industrialize depending on whether expectations are either optimistic or pessimistic.

We can now analyze the effect of a natural resource boom on the growth path of the economy. In general, we know that a positive natural resource boom will shift resources to the non-traded sector. This follows as long as preferences are such that consumers will want to spend at least some of the higher wealth on non-traded goods. Since these goods must by definition be produced at home, the only way to achieve higher consumption is to shift labor to this sector. Formally, this can be seen from the fact that the reduced form for $L^{\mathrm{N}}$ in Appendix $\mathrm{A}$ is increasing in $R$.

If the non-traded sector is the increasing returns sector, the boom will shift resources into the increasing returns sector, that is, $L^{\mathrm{N}}$ will rise for any given $n$. From Eq. (6), $x$ will also rise for any given $n$, and, from Eq. (7), the profit function will shift upwards (see Fig. 1). Since profits rise for any given value of $n$, both value functions will shift up in $V-n$ space. We illustrate this in Fig. 4. There are then two ranges of $n$ where the boom is beneficial. Since the pessimistic value function shifts to the left, some values of $n$ shift from supporting both equilibria to supporting only optimistic equilibria. In this region of $n$, the natural resource boom can stop an economy that otherwise would have been in the process of de-industrialization. Since the optimistic value function shifts to the left, there are some values of $n$ that previously would only have supported de-industrialization which now can also lead to full industrialization. In this sense the resource booms can serve the function of a big push, launching the economy into a self-fulfilling process of industrialization that it could not have achieved without the boom.

It is equally clear that a resource boom can stall industrialization or even send an economy into a spiral of de-industrialization. This can occur when the traded sector has increasing returns, and is illustrated in Fig. 5. Now the boom draws resources out of the increasing returns sector, reduces the scale of activity in each intermediate sector and reduces profits. In Fig. 5, both value functions shift to the right. There is now a smaller range of $n$ that supports industrialization and a larger range that supports de-industrialization. The economy can switch from being on a path towards industrialization to a path towards de-industrialization. In this case the economy will suffer from the curse of natural resources: the boom will raise incomes temporarily but will frustrate the process of industrialization.

\subsection{Conclusions and extensions}

During the past thirty years, Latin American economic growth was minimal, while East Asian growth (at least until 1997) was very rapid. One major difference between the regions was the nature of their trading relations with the rest of the world. Latin America, by and large, remained as it had been throughout its history, 


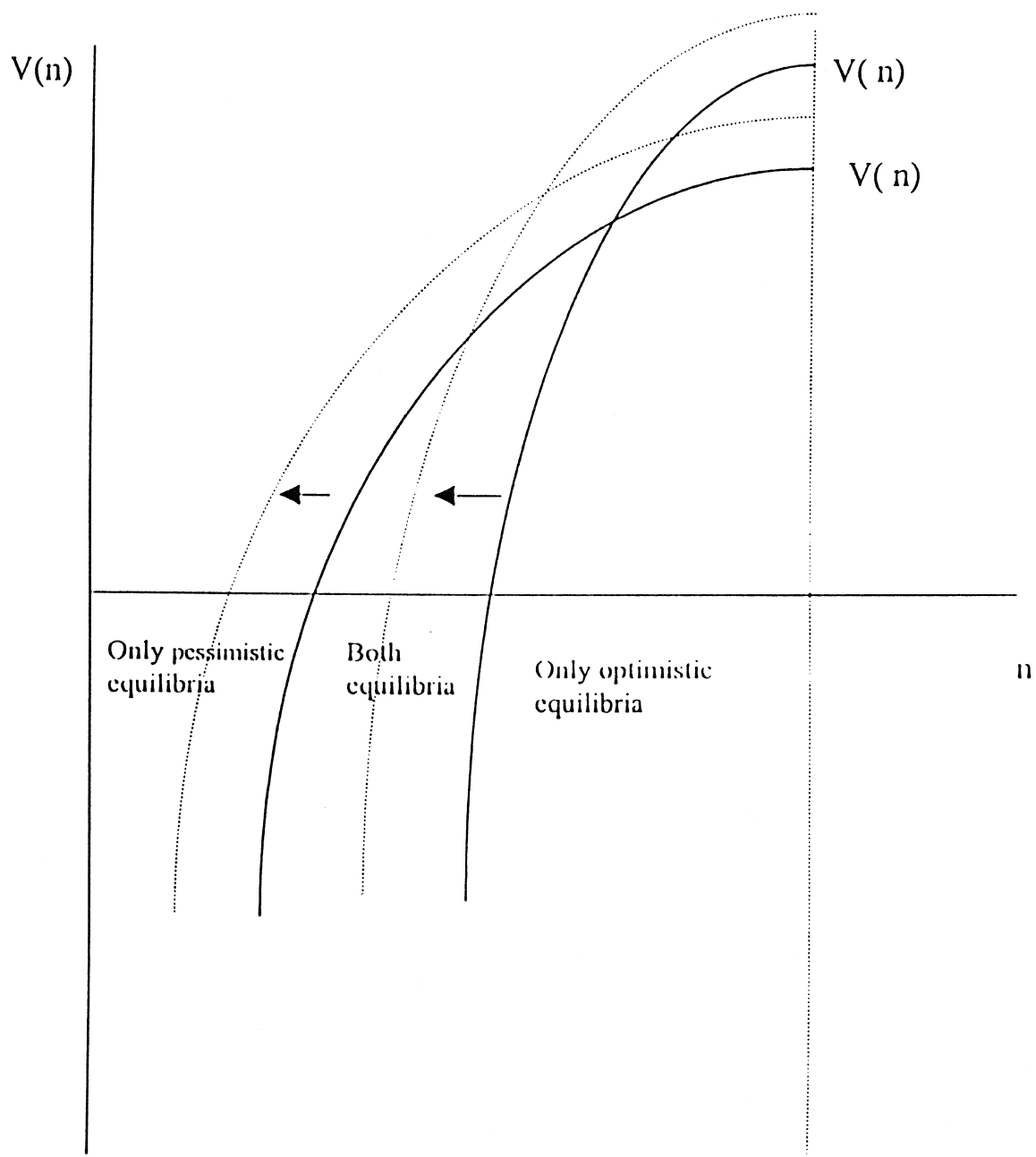

Fig. 4. Effect of a natural resource boom when the non-traded sector has increasing returns.

an exporter of primary commodities, or manufactured products based on those primary commodities. East Asia by contrast experienced export-led growth based first on labor-intensive exports, and then increasingly on capital-intensive and technology-intensive exports. One long-standing theme in the historiography of Latin America is that commodity-based development is one of the underlying problems for growth in the region. This paper has explored the famous theme, both theoretically and empirically.

On the theoretical side, we have illustrated cases in which primary commodities would indeed be either the engine or the brake on overall economic growth. The 


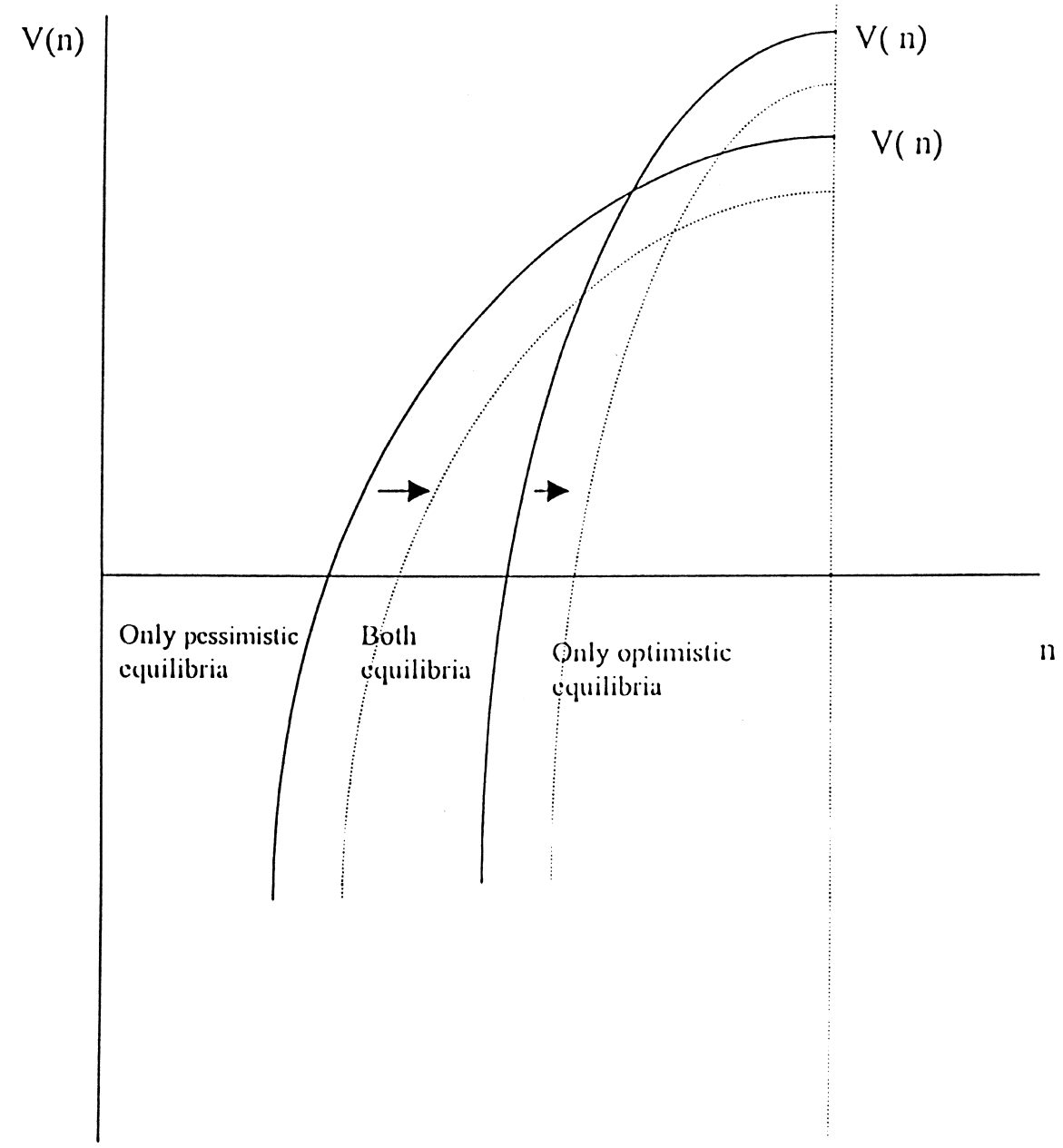

Fig. 5. Effect of a natural resource boom when the traded sector has increasing returns.

question of whether the resource earnings could 'sow the seeds' of development, depends in our model on whether the increasing-returns-to-scale (IRS) production is in the tradeables or the non-tradeables sectors. When the IRS sector is non-tradeable, a resource boom can indeed pull more goods into that sector, and thereby set off a dynamic growth process. When the IRS sector is in tradeable manufactures, a resource boom can frustrate growth, via the Dutch disease phenomenon.

Empirically, resource booms seem to have done little to generate long-term growth, and may in fact have hindered growth on average. The resource booms in 
Bolivia, Mexico and Venezuela did not permanently raise the level of per-capita GDP, and were followed by a growth slowdown rather than increase. The resource boom in Ecuador appears to have raised the level of GDP initially but was not followed by faster growth. Of course, at this level of modeling, we can't distinguish several possible channels of effect: Dutch disease, political instability, costs of high variability of export earnings (with imperfect financial and insurance markets), and other possible channels. For this reason, we will continue the work of this paper and a companion paper (Sachs and Warner, 1997a,b) by examining more closely the possible pathways linking economic structure (especially resource endowments) and long-term economic growth performance. In our forthcoming work, we will analyze how certain natural-resource-abundant economies (e.g., Australia, Canada, New Zealand, Norway, Sweden) seem to have succeeded in long-term growth heavily dependent on commodity exports. We will analyze whether some of the recently successful commodity exporters (such as Chile) can hope to replicate such long-term performance.

\section{Appendix A. List of variables used in the regressions}

Growth per-capita

Log Real GDP, 1965

Openness to trade

Landlocked
Average annual growth in real GDP per person between 1965 and 1990. GDP data are from the Penn World Tables, Mark 5.6, and are adjusted for differences in the purchasing power across countries (see Summers and Heston, 1981). The population data is from the World Data CD-ROM, World Bank, 1995.

The log of real GDP per head of the economically active population in 1965. As above, GDP data are from the Penn World Tables, Mark 5.6, and are adjusted for differences in the purchasing power across countries (see Summers and Heston, 1981). The economically active population is defined as the population between the ages $15-64$. The population data is from the World Data CD-ROM, World Bank, 1995.

The fraction of years during the period 19651990 in which the country is rated as an open economy according to the criteria in Sachs and Warner (1995).

Dummy variable that takes the value 1 if a country is completely landlocked; 0 otherwise. Source: Authors. 


\section{Life Expectancy \\ Central Gov. Savings}

Tropics

Institutional Quality
Life Expectancy in years, circa 1970. Source: Jong-wha Lee.

Average value of central government savings over the period 1970-1990. Savings is defined as current revenues minus current expenditure, and is measured in percent of GDP. Source: World Data CD-ROM, World Bank, 1995.

Approximate fraction of a country's land area that is subject to a tropical climate. Source: Authors.

Institutional quality index. This is an un weighted average of 5 sub-indexes developed from data by Political Risk Services, measuring the following. The rule of law index 'reflects the degree to which the citizens of a country are willing to accept the established institutions to make and implement laws and adjudicate disputes' The bureaucratic quality index measures 'autonomy from political pressure', and 'strength and expertise to govern without drastic changes in policy or interruptions in government services.' The corruption in government index measures whether 'illegal payments are generally expected through-

out...government', in the form of 'bribes connected with import and export licenses, exchange controls, tax assessments, police protection, or loans.' The risk of expropriation index measures high risk of 'outright confiscation' or 'forced nationalization.' The government repudiation of contracts index measures the 'risk of a modification in a contract taking the form of a repudiation, postponement or scaling down.' These five sub-indexes are scaled and averaged together into our overall institutional quality index. This index was originally constructed by the Center for Institutional Reform and the Informal Sector (IRIS) from data printed in the International Country Risk Guide published by Political Risk Services. See Knack and Keefer (1994) for further details. 
Share of exports of primary products in GNP in 1970. Primary products or natural resource exports are exports of 'fuels' and 'non-fuel primary products' from the World Data 1995 $C D-R O M$ disk, produced by the World Bank. Non-fuel primary products correspond to SITC categories 0, 1, 2, 4, and 68. Fuels correspond to SITC category 3 . These categories are from revision 1 of the SITC. GNP is taken from the same source. Both numerator and denominator are measured in nominal dollars. The World Data uses a smoothed exchange rate to convert local currency GNP to dollars. This describes the basic data. In addition, we made the following modifications. Bangladesh: 1975 data. Bahrain: 1980 data. Botswana: Exports of Diamonds in 1970 taken from Modise (1996). Cape Verde: export data for 1972 taken from World Tables 1994, World Bank; GNP data taken from the World Data 1995 CD-ROM disk. China: 1980-data. Cyprus: 1975 data. Jordan 1985 data. Iran: GNP in 1970 calculated with data in the Penn World Tables, mark 5.6 together with price and exchange rate data in the World Data 1995 CD-ROM disk. Myanmar: 1970 GNP converted to dollars by the authors using the 1970 nominal exchange rate. Taiwan: Exports taken from Taiwan Statistical Data Book 1995, page 194 and GNP taken from 1996 volume, page 1. Uganda: 1980 data. South Africa: the published trade statistics do not include raw diamonds and gold, so these were added by the authors using data in Bulletin of Statistics, The Republic of South Africa, Pretoria, December 1972 and June 1992. Singapore: used net exports of natural resources because Singapore simply re-exports a lot of natural resources which originate elsewhere. Trinidad: used net exports for the same reason as Singapore. United Arab Emirates: 1973 data. Zimbabwe: 1980 data. 
LA

Dummy variable equal to 1 for 11 Latin American countries in this paper, 0 otherwise.

Growth in e.a. pop - pop growth Average annual growth of the economically active population minus average annual growth of the total population 1965-1990. Source: World Bank, World Data 1995, CD-ROM.

Mineral Exports/GDP Version of the natural resource exports variable using only fuels and primary metals. Source: World Bank, World Data 1995, CDROM.

Standard Deviation of TT

Standard deviation of each countries terms of trade index $(1987=100)$ over the period 1970-1990. Source: World Bank STARS data diskette, 1993.

Manufacturing exp. share

Fraction of exports of manufactures in total exports, 1990 and 1970. Source: World Bank, World Data 1995, CD-ROM.

\section{A.1. Summary of the model}

The two main cases of the model are described below. In the first case the traded sector is the increasing returns sector and the non-traded sector is the constant returns sector. In the second case the opposite is true.

Case 1: Traded sector has increasing returns to scale. a. Traded sector $\left(p^{T}\right.$ is the price of the finished good; $p$ is the price of the intermediate good; $Q^{\mathrm{T}}$ and $x$ are the quantities; $N$ is the total number of varieties of the intermediate good; $n$ is the number of these that are produced with the increasing returns technology, and each of these firms earn $\pi$ in profits).

$$
\begin{aligned}
& p^{\mathrm{T}}=1 \\
& Q^{\mathrm{T}}=\left(\sum_{i=1}^{N} x_{i}^{a}\right)^{\frac{1}{a}}, a \in(0,1) \\
& Q^{\mathrm{T}}=N^{\frac{1}{a}} x \\
& p^{\mathrm{T}}=p N^{\frac{-(1-a)}{a}} \\
& p=w \quad L^{\mathrm{T}}=(N-n) x+n(\alpha+\beta x) . \\
& \pi=p x-w(\alpha+\beta x)
\end{aligned}
$$


b. Non-traded sector.

$$
\begin{aligned}
& p^{\mathrm{N}}=\theta w \\
& Q^{\mathrm{N}}=\theta L^{\mathrm{N}}
\end{aligned}
$$

c. Demand.

$$
p^{\mathrm{T}} C^{\mathrm{T}}=\psi p^{\mathrm{N}} C^{\mathrm{N}}
$$

d. Market clearing.

$$
\begin{aligned}
& L=L^{\mathrm{N}}+L^{\mathrm{T}}, \\
& Q^{\mathrm{N}}=C^{\mathrm{N}}, \\
& C^{\mathrm{T}}=Q^{\mathrm{T}}+R .
\end{aligned}
$$

Case 2: Non traded sector has increasing returns to scale. a. Non-traded sector $\left(p^{\mathrm{N}}\right.$ is the price of the finished good; $p$ is the price of the intermediate good; $Q^{\mathrm{N}}$ and $x$ are the quantities; $N$ is the total number of varieties of the intermediate good; $n$ is the number of these that are produced with the increasing returns technology, and each of these firms earn $\pi$ in profits).

$$
\begin{aligned}
& Q^{\mathrm{N}}=\left(\sum_{i=1}^{N} x_{i}^{a}\right)^{\frac{1}{a}}, a \in(0,1) \\
& Q^{\mathrm{N}}=N^{\frac{1}{a}} x \\
& p^{\mathrm{N}}=p N \frac{-(1-a)}{a} \\
& p=w \\
& L^{\mathrm{N}}=(N-n) x+n(\alpha+\beta x) . \\
& \pi=p x-w(\alpha+\beta x)
\end{aligned}
$$

b. Traded sector.

$$
\begin{aligned}
& p^{\mathrm{T}}=1 \\
& p^{\mathrm{T}}=\theta w \\
& Q^{\mathrm{T}}=\theta L^{\mathrm{T}}
\end{aligned}
$$

c. Demand.

$$
p^{\mathrm{T}} C^{\mathrm{T}}=\psi p^{\mathrm{N}} C^{\mathrm{N}}
$$

d. Market clearing.

$$
\begin{aligned}
& L=L^{\mathrm{N}}+L^{\mathrm{T}}, \\
& Q^{\mathrm{N}}=C^{\mathrm{N}}, \\
& C^{\mathrm{T}}=Q^{\mathrm{T}}+R .
\end{aligned}
$$


Solution: In both cases, it is convenient to solve for the reduced form for employment in the non-traded sector, and then to solve the rest of the model recursively. In the case where the traded sector has increasing returns, the implicit solution for employment in the non-traded sector $\left(L^{\mathrm{N}}\right)$ is:

$$
N^{\frac{1}{a}}\left(\frac{L-L^{\mathrm{N}}-\alpha n}{N-n(1-\beta)}\right)+R=\psi p^{\mathrm{N}} \theta L^{\mathrm{N}} .
$$

In the case where the non-traded sector has increasing returns, the solution is:

$$
\theta\left(L-L^{\mathrm{N}}\right)+R=\psi p^{\mathrm{N}} N^{\frac{1}{a}}\left(\frac{L^{\mathrm{N}}-\alpha n}{N-n(1-\beta)}\right)
$$

With these solutions in hand, the equilibrium scale of output for the firms operating with the increasing returns technology is:

$$
x=\frac{L^{j}-n \alpha}{N-n(1-\beta)},
$$

and profits per firm are:

$$
\pi=(p-w \beta) x-w \alpha .
$$

The value functions are then obtained by allowing $n$ to vary over time and then calculating the present discounted value of profits.

In general,

$$
n=f(t)
$$

with a lower bound of 0 and an upper bound of $N$. Under optimistic expectations, $n$ is expected to rise over time until it hits its upper bound $N$, where it stays forever. Under pessimistic expectations, $n$ is expected to fall until it hits its lower bound of 0 .

The value function is conditional on whether expectations are optimistic or pessimistic (denoted by the superscript $O$ or $P$, and on the initial value of $n$, denoted $n\left(t_{0}\right)$. Under optimistic expectations it is defined as follows ( $\rho$ is the discount rate)

$$
V^{\mathrm{o}}\left(n\left(t_{0}\right)\right)=\int_{n\left(t_{0}\right)}^{\infty} \mathrm{e}^{-\rho\left(t-t_{0}\right)} \pi(x(n(t))) \mathrm{d} t
$$


ปิ)
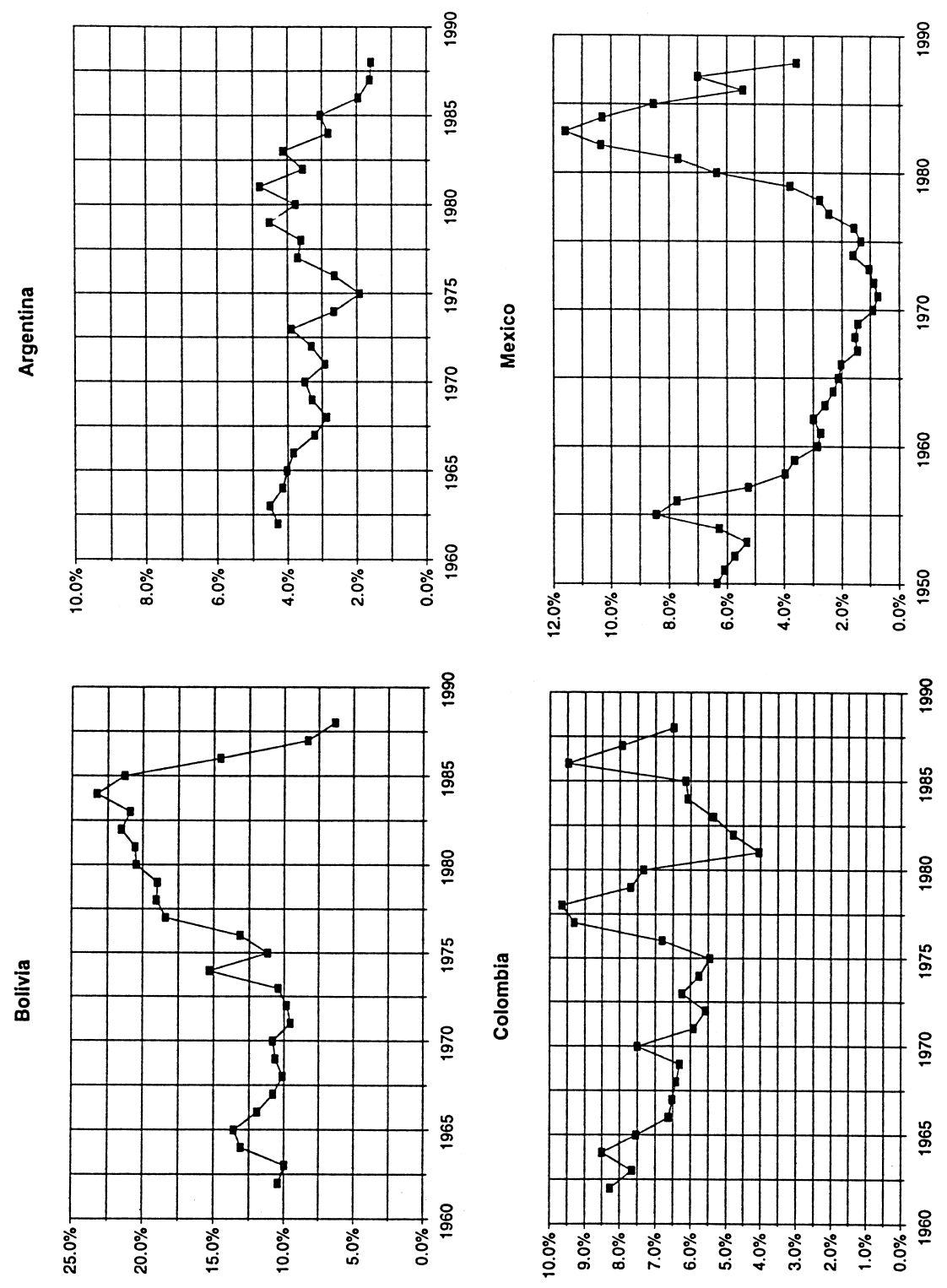

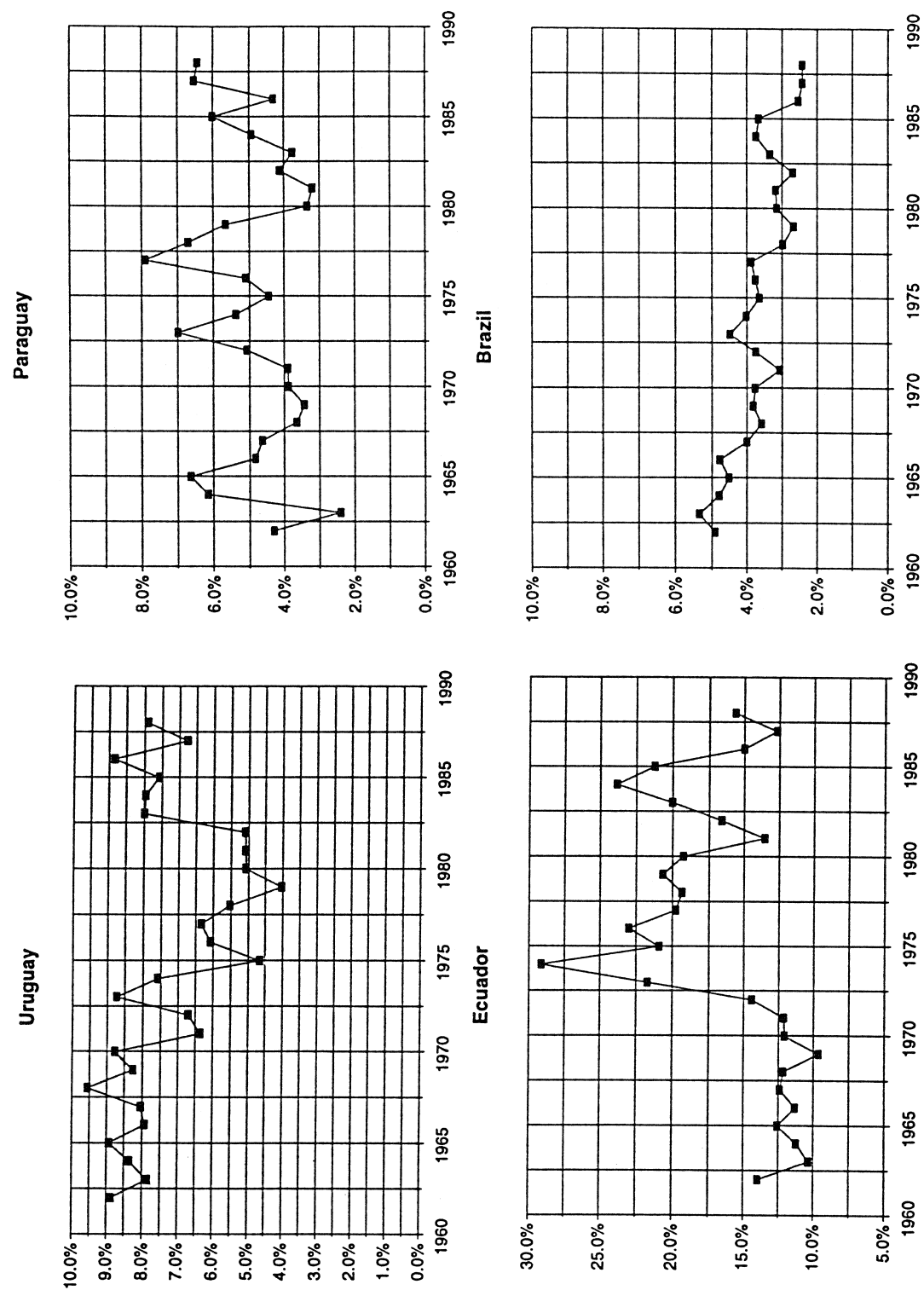


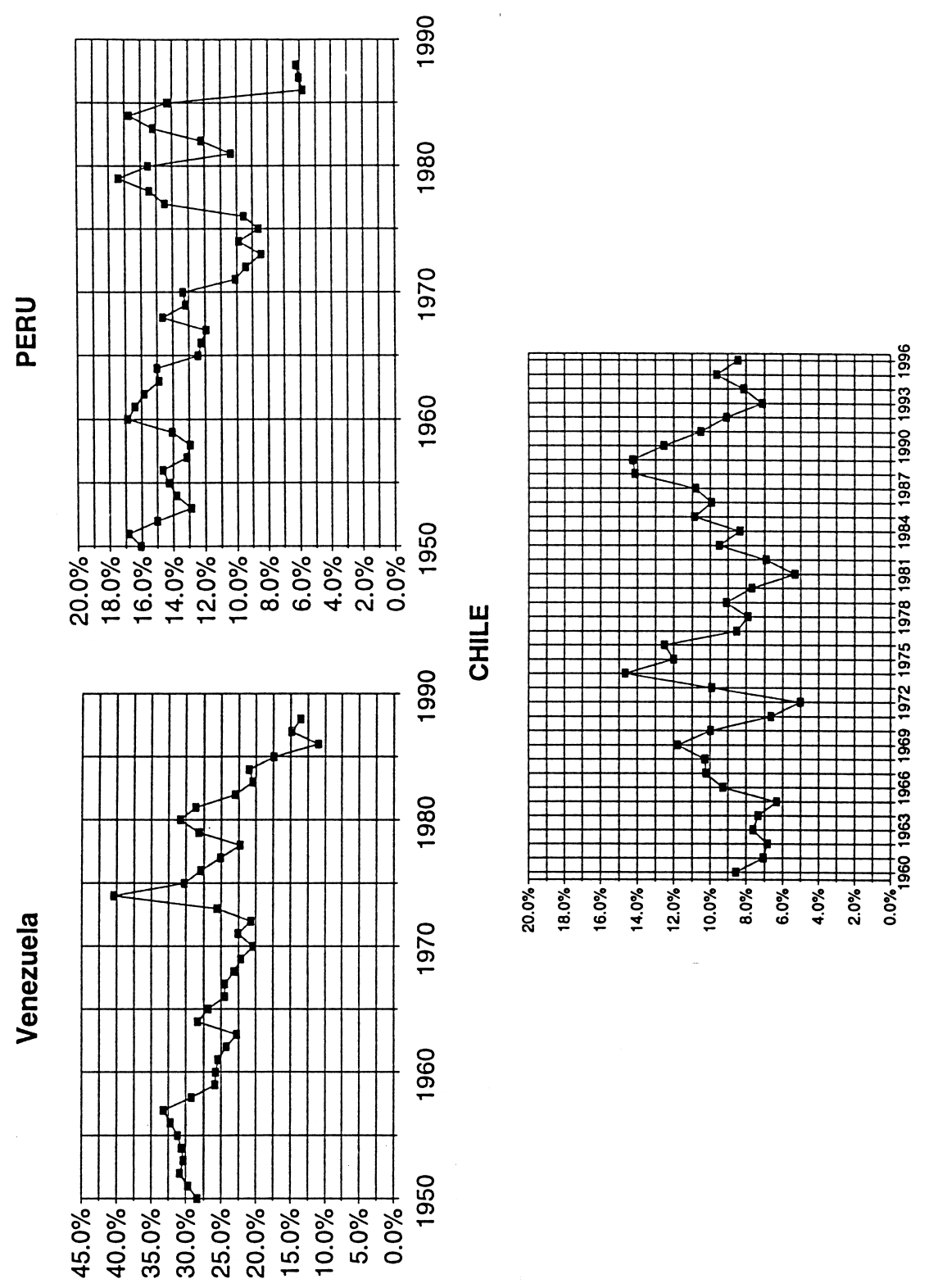



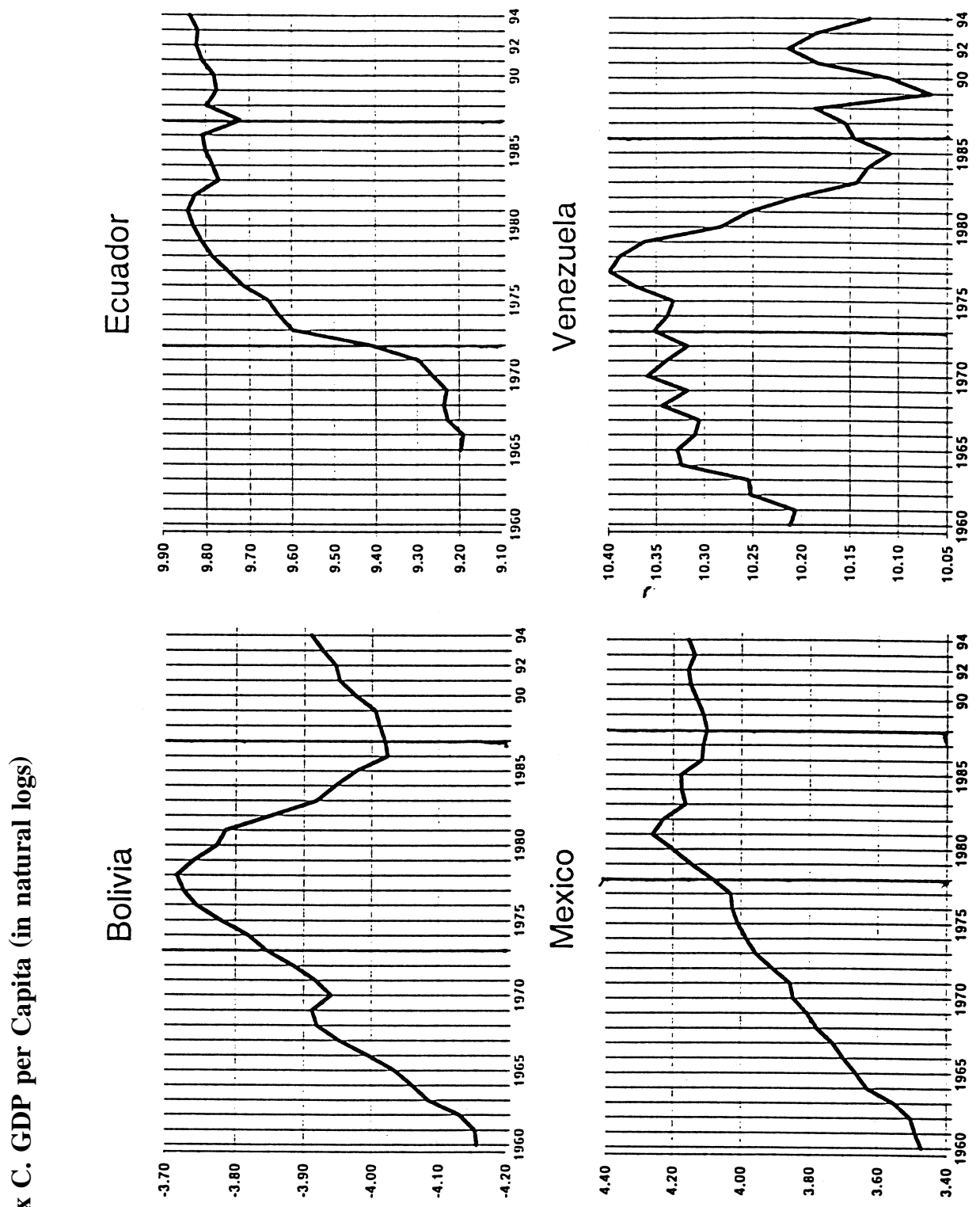

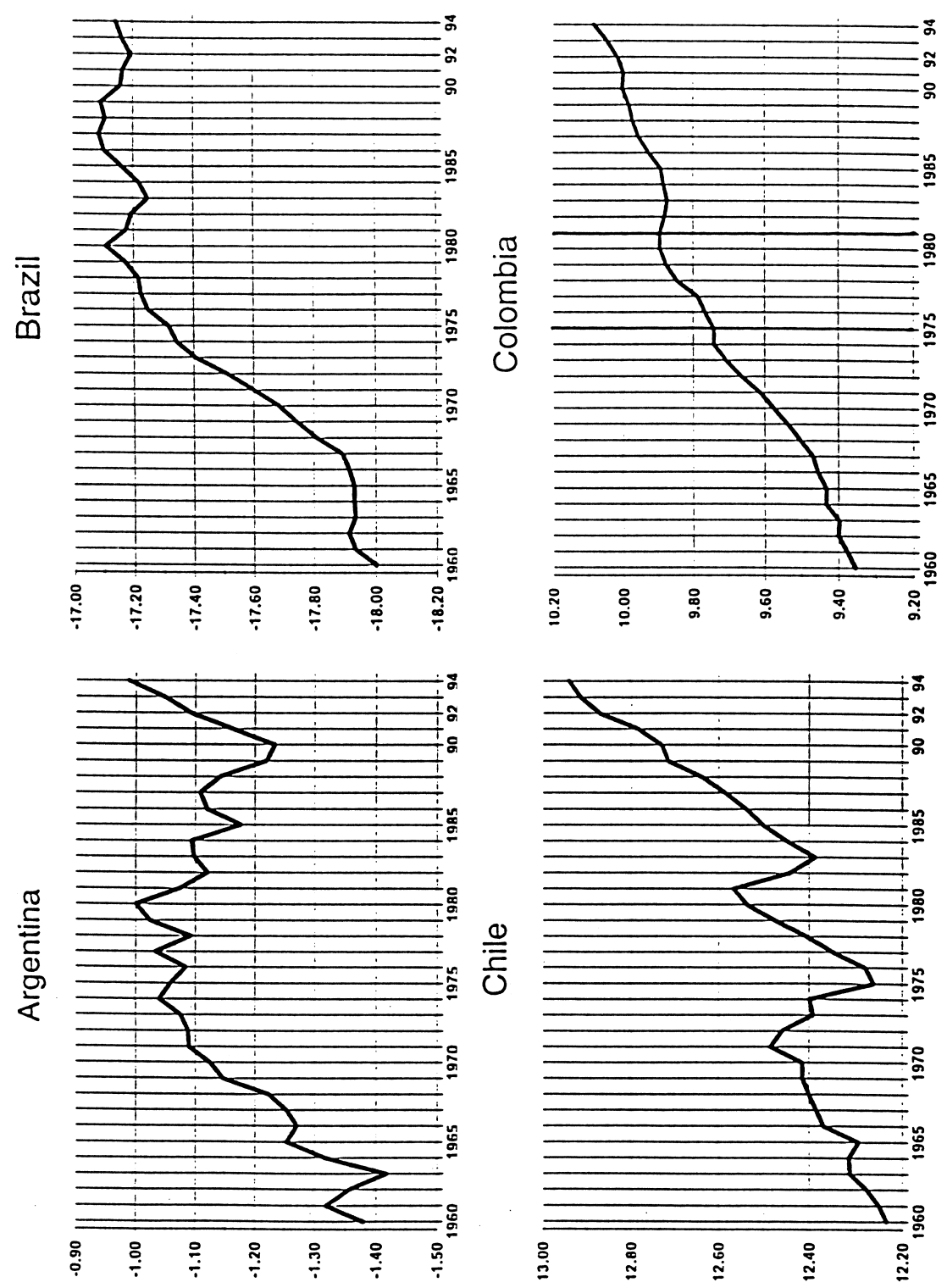

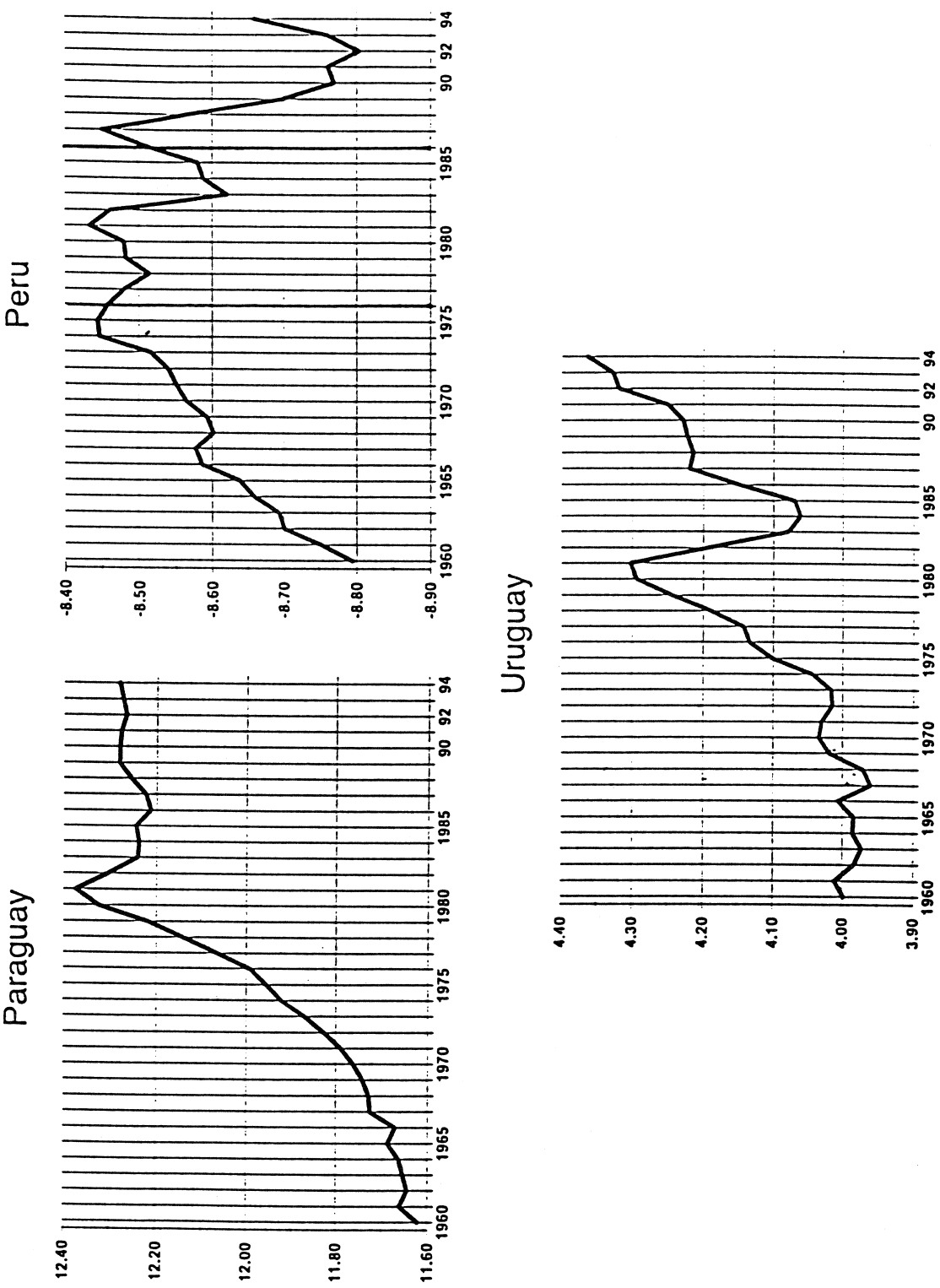


\section{References}

Auty, 1990.

Bulmer-Thomas, V., 1994. The Economic History of Latin America since Independence. Cambridge Latin American Studies, 77, Cambridge University Press, New York.

Collier, S., Sater, W., 1996. A history of Chile, 1808-1994. Cambridge Latin American studies, 82, Cambridge University Press, Cambridge.

Gelb, A.H., 1988. Oil Windfalls, Blessing or Curse. Oxford University Press, Oxford.

Ethier, W.J., 1982. National and international return to scale in the modern theory of international trade. American Economic Reviews 72, 389-405.

Hirschman, A.O., 1958. The strategy of economic development. Yale studies in economics, 10, Yale University Press, New Haven.

Knack, S., Keefer, P., 1994. Institutions and Economic Performance: Cross-country Tests using Alternative Institutional Measures. IRIS Working Paper 109, Economics and Politics, forthcoming.

Murphy, K., Schleifer, A., Vishny, R.W., 1989. Industrialization and the big push. Journal of Political Economy 97 (5), 1003-1026.

Prebisch, R., 1950. United Nations, The Economic Development of Latin America and its Principal Problems, Lake Success, NY.

Randall, L., 1977. A comparative economic history of Latin America: 1500-1914. Monograph publishing on demand: sponsor series. University Microfilms International, Ann Arbor, MI.

Rosenstein-Rodan, P., 1943. Problems of industrialization of Eastern and Southeastern Europe. Economic Journal 53, 202-211.

Rosenstein-Rodan, P., 1961. Notes on the Theory of the 'Big Push'. In: Ellis, H.S., Wallich, H.C. (Eds.), Economic Development for Latin America. St. Martin's Press, New York.

Sachs, J., Warner, A., 1995. Natural Resource Abundance and Economic Growth. National Bureau of Economic Research working paper 5398. Cambridge, MA.

Sachs, J., Warner, A., 1997. Natural Resource Abundance and Economic Growth. Revised version. Unpublished manuscript. Harvard Institute for International Development. Cambridge, MA.

Sachs, J., Warner, A., 1997b. Sources of slow growth in African economies. Journal of African Economics 6 (3), 335-380.

Singer, H., 1950. The distribution of trade between investing and borrowing countries. American Economic Review 40, 473-485.

Summers, R., Heston, A., 1981. The Penn World Table (Mark 5.6): an expanded set of international comparisons, 1950-1988. Quarterly Journal of Economics 106 (2), 327-368.

World Bank, 1995. World Data CD-ROM. Washington, DC. 